\title{
SEMBLANZA DE ALFONSO TRIBÍN FERRO
}

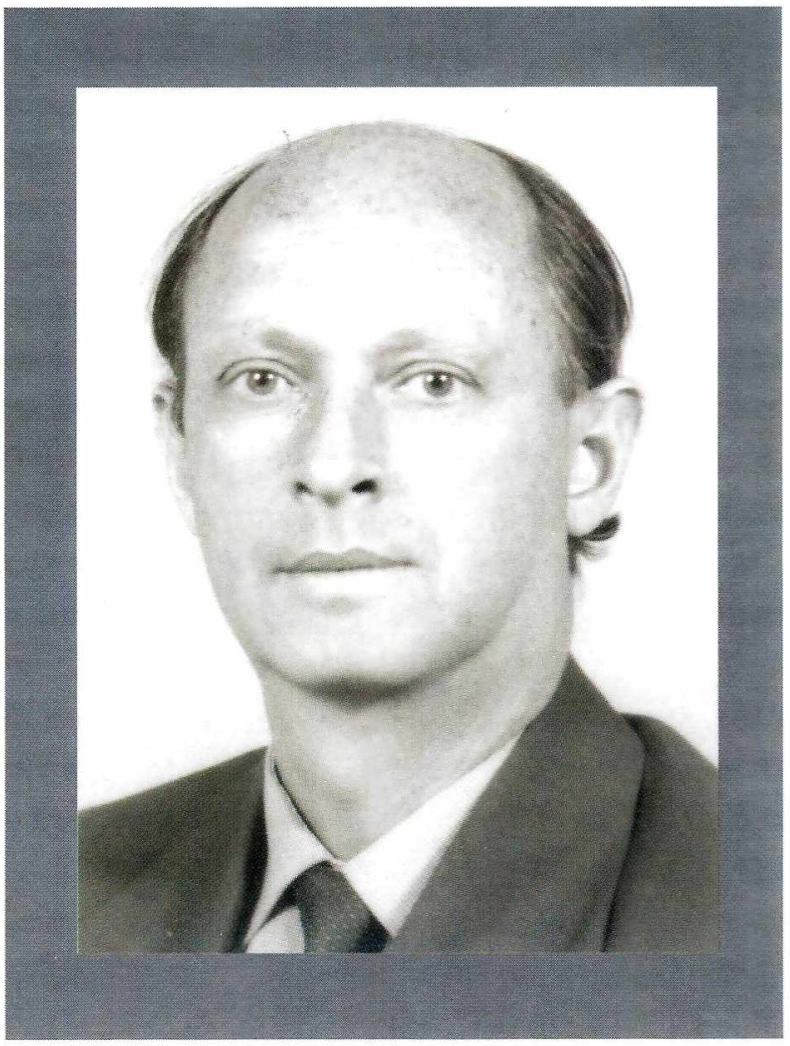

urió Alfonso en el momento de la existencia cuando la experiencia y el conocimiento de la vida producen ideas y concretan acciones en los distintos campos del saber, que él supo cultivar con esmero y dedicación. Para Repertorio de Medicina y Cirugía habrá un vacío por la ausencia de sus consejos e indicaciones que nunca faltaron como Coordinador General. Siendo alumno y colega lo conocí bien y compartimos muchas horas en el diario transcurrir de nuestras actividades académicas.

Nació en Bogotá en 1947 y desde joven quiso seguir los pasos de su padre, el Profesor Alfonso Tribín Piedrahita, a quien recordamos con cariño y grati- tud quienes atendimos la cátedra de oftalmología en el otrora gran hospital de San Juan de Dios de la Facultad de Medicina, Universidad Nacional, de donde fue después su decano por varios años. Ambos creyeron en el nuevo proyecto académico de mediados de los años 60 cuando la Sociedad de Cirugía de Bogotá, su Hospital de San José y el Colegio Mayor de Nuestra Señora del Rosario decidieron reabrir la centenaria facultad de medicina de este último, con un currículo novedoso y de avanzada que colmara las necesidades médicas del país. Así ingresó Alfonso a la segunda promoción en 1966 con las figuras tutelares de ese tiempo como fueron Monseñor José Vicente Castro Silva, Guillermo Fergusson y un profesorado de lujo, en 
compañía de Alfonso Tribín Piedrahita que como Consiliario entró a formar el primer Consejo Directivo de la nueva facultad.

Se destacó siempre como uno de los alumnos sobresalientes por el deseo de aprender, conocer, progresar y su don de liderazgo. Se graduó de médico y cirujano en 1971 y como oftalmólogo en 1976. De allí en adelante jamás se desvincularía de las instituciones que fueron gestoras de su formación profesional y científica. Así lo deben recordar sus compañeros de promoción, en especial aquellos que desde entonces continuaron con él en la Universidad del Rosario y en el Hospital de San José, como Alina Arango, Francisco Durán, Alfonso Pallares y Edgar Muñoz.

Su gran capacidad didáctica le fue de gran utilidad en la cátedra de oftalmología en la Fundación Universitaria de Ciencias de la Salud y en la Universidad del Bosque, donde sus alumnos lo recuerdan por sus clases magistrales, su docencia en las salas quirúrgicas y su preocupación permanente por el aprendizaje de sus estudiantes que trataba con cariño y amistad. Así fue como también cuando se desempeñó como vicedecano de medicina del Rosario en 1991 y 92, y luego como decano de 1993 a 1999.

Fue especialmente destacada su actuación desde diciembre de 1989 hasta septiembre de 2005 como decano de la naciente facultad de medicina de la Fundación Universitaria de Ciencias de la Salud y después en el importante cargo de vicerrector académico que ejerció hasta el día de su muerte. La comunidad académica estará siempre agradecida por la vocación y dedicación que caracterizaron su admirable personalidad.

En el campo asistencial fue jefe de los servicios de oftalmología en los hospitales de San José y Simón Bolívar de Bogotá. De este último fue director en 1986-86 y perteneció a la Junta Directiva del Hospital de San José siendo vicepresidente de la Sociedad de Cirugía de Bogotá en 1992 y después como deca- no de la facultad de medicina del Rosario hasta 1996. El afecto que siempre prodigó a los enfermos obliga a recordarlo no sólo como un gran especialista, sino como un hombre sensible y humanitario.

En el campo de las agremiaciones profesionales y científicas fue muy activo y perteneció a numerosas sociedades como las de oftalmología de Bogotá, la Colombiana, la Americana, la Panamericana y el American Collage of Surgeons. A la Sociedad de Cirugía de Bogotá ingresó como asociado pasando a miembro de número en 1990, presidió la Asociación de médicos rosaristas de 1990 a 1991 y después fue su presidente honorario de 1994 a 1997. Fueron muchos los trabajos extramurales, la participación en cursos y congresos de la especialidad y las publicaciones científícas y académicas.

Alfonso fue un gran deportista y se destacó en numerosas disciplinas, pero lo que siempre colmó sus ansias y su pasión fue el fútbol, no sólo como espectador fanático como somos muchos de sus amigos, sino como participante activo desde su juventud en las ligas inferiores de Millonarios, su equipo del alma, que en lejana ocasión jugó en el estadio del Campín de Bogotá en la titular. Después continuó en equipos de aficionados y de veteranos que él convocaba, alineaba y animaba.

Pero ante todo, evocamos la memoria de Alfonso como amigo leal y servicial, solícito y atento para aconsejar y ayudar, miembro de familia cariñoso y ejemplar. Para su compañera de la vida, Marcela Gómez y sus hijos Marcela y Alfonso, queremos expresarles en estas páginas que siempre elogió, el sentimiento de pesar de toda una comunidad académica y asistencial, con la certeza de que su imagen y sus enseñanzas perdurarán en el tiempo y en nuestros corazones.

Paz en la tumba de Alfonso Tribín Ferro.

* El Editor 